Article

\title{
Clock Hand Lateral, A New Layout for Semi-Permanent Sprinkler Irrigation System
}

\author{
Lei Gan ${ }^{1}(\mathbb{D})$, Saeed Rad ${ }^{1} *(\mathbb{1})$, Xiaobing Chen ${ }^{2}$, Rongjie Fang ${ }^{2}$, Lei Yan ${ }^{3}$ and Shihua $\mathrm{Su}^{4}$ \\ 1 Guilin University of Technology, Guangxi Collaborative Innovation Center for Water Pollution Control and \\ Safety in Karst Area, Guilin 541004, Guangxi, China; allen_gl2006@163.com \\ 2 Guilin university of Technology, Guangxi Key Laboratory of Environmental Pollution Control Theory and \\ Technology, Guilin 541004, Guangxi, China; Jayvision_chen@126.com (X.C.); gIfrj@126.com (R.F.) \\ 3 College of Environmental Science and Engineering, Guilin University of Technology, Guilin 541004, \\ Guangxi, China; Martin_946@163.com \\ 4 Guilin Irrigation Experiment Station, Guilin 541004, Guangxi, China; glsyz@163.com \\ * Correspondence: saeedrad1979@gmail.com; Tel.: +86-135-1773-5068
}

Received: 12 May 2018; Accepted: 7 June 2018; Published: 12 June 2018

\begin{abstract}
The experiment was done based on a new layout for a semi-permanent set-move sprinkler irrigation system with a lower capital and annual cost requirement. In this work, a center-pivot system layout was applied to set up a semi-permanent system with a hand-move lateral. The clock hand lateral (CHL) sprinkler irrigation system was implemented using a shorter mainline length with a smaller diameter, lesser number of lateral pipes, minimum number of fittings and a single valve outlet. This combination offers an affordable irrigation system with minimizing the required components. The new irrigation system design was examined at the Agricultural Academy of Science experiment farm at Guangxi, China. The sprinkler system mainline pipe directly extended from the water resource to the center of the plot to feed a single lateral, connected through a pivot elbow. The lateral was rotating around the plot manually, the same way as clock hands do. An ordinary set-move split lateral for the same plot was designed for comparison and control. Based on results, a $37.5 \%$ capital cost reduction with an $11.2 \%$ annual cost decrement was obtained for CHL compared to the set-move semi-permanent. Water application depth was measured via distribution uniformity coefficient (DU) examination, using a catch can method. The low quarter DU for CHL was counted for $86 \%$.
\end{abstract}

Keywords: sprinkler irrigation; semi-permanent; set-move; split lateral; clock hand lateral; cost reduction

\section{Introduction}

Rapid growth of sprinkler irrigation systems implementation, due to finite freshwater resources and the need for agricultural product maximization, is a global imperative. Utilizing about $70 \%$ of our inadequate freshwater resources in agriculture, mostly with low efficiency irrigation methods [1] is in contrast with the necessity for sustainable development with optimized water utilization. As per FAO [2] statistics in the year of 2000 , only $20 \%$ of the total earth planet croplands were irrigated; however, this will provide $40 \%$ of the total food produced [3]. In fact, out of 149 million $\mathrm{km}^{2}$ total land area, approximately 17.23 million $\mathrm{km}^{2}$ (or $11.6 \%$ ) is cultivated, in which 15.75 million $\mathrm{km}^{2}$ are arable lands. By the end of 2008, the estimated irrigated farms were more than 3.24 million $\mathrm{km}^{2}$, which is one fifth of the total arable lands [4]. On the other hand, out of $2.5 \%$ freshwater resources on earth (the remaining $97.5 \%$ is ocean and saline waters) only $0.77 \%$ of it is accessible and the remaining $1.76 \%$ are glacier ices, permanent snow or ground ice [5]. Nevertheless, by the year 2050, when the total 
population is 9 billion people, we will need almost $70 \%$ more agricultural products on average (it is $100 \%$ in developing countries) which need more water withdrawals [4]. These statistics are clear signs of the necessity of research on new methods to promote and enhance irrigation systems and must lead to innovative and cost-effective designs [6,7] as an important aspect of the system's development.

Various irrigation methods have been applied in order to optimize water resources utilization as well as product maximization. Traditional surface irrigation methods (such as furrow, flood, level basin, ponding, etc.) offer an inexpensive but less efficient option where enough water is available to supply. These systems require more manual work and the efficiency is barely up to $60 \%$ in most of the cases $[8,9]$. In contrast, trickle or drip irrigation systems (like bubbler method, micro spray, emitters, etc.) provide a much lesser amount of water for each plant. Water utilization efficiency can reach up to $90 \%$ in this method with a far less manual process. However, the system is one of the most expensive irrigation systems with high maintenance, which works under low pressure $[10,11]$. Beside these two methods, sprinkler irrigation systems with different types, applications, and designs offer a wide range of options from low to high cost requirements in different soil types, for a variety of plants. Sprinkler systems normally working under medium to high pressure and water application efficiency in these methods varies from 60 up to $85 \%$ normally $[10,12,13]$. Center-pivot, wheel move, permanent or solid set, semi-permanent, portable, semi-portable, etc. are some types of sprinkler irrigation systems [14]. Nevertheless, in most cases, without governments financial support, small farm owners are not able to afford pressured irrigation systems since most of them are costly.

As per the literature, some of the most significant influencing factors in terms of investment and cost, which imposes the highest amount on an irrigation system, include pipe diameter and length, as well as the number of sprinklers and laterals [15]. Various strategies and methods have been applied to reduce the system costs and provide the most cost-effective option for the farmers. Irrigation systems cost comparison has been done in many studies [15-17] to analyze and specify the highest expediency for the systems. Among them, portable and semi-permanent systems or set-move with removable laterals $[18,19]$ are the two most profitable. In semi-permanent systems the water resource as well as main pipes (normally as buried) are fixed with the mobility of laterals [20], while they are all mobile for portable system. This mobility will result in having a lighter system using less components, which consequently will reduce the total system expenses with higher manual works, comparatively.

Developing irrigation systems will help to provide more agricultural product with less water, for the growing population. The novel systems must be feasible for farmers, taking into account the investment and operational costs of the system implementation. Especially since it will take a few years for farmers to recover the investment costs by additional yield or other benefits from the irrigated farms (break-even point); wherever governmental subsidy is not available, the cheaper irrigation methods are preferable.

The proposed system "clock hand lateral layout sprinkler system" or CHL, is offering a remarkable cost reduction which makes it a more desirable alternative. It is similar with the current ordinary split lateral set-move layout in the concept but with a shorter main/sub-main pipe. It also requires lower mainline diameter, lesser number of laterals and consequently lesser hydrants and fitting joints. This novel design is an integration of both set-move and center-pivot irrigation systems in which the lateral will be transferred manually unlike automated center pivot systems. It makes it efficacious as it has been designed for small to medium scale farms compared to a complicated heavy center-pivot system which is justifiable for huge farms only. It is also lighter and less expensive than an ordinary split lateral which makes it match the yeoman systems requirement. In the current semi- permanent split lateral layout (Figure 1a), laterals are carried lengthwise manually over the mainline from one side to another. Along the mainline there are enough valve outlets or hydrants for the laterals to be connected. While in the CHL system (Figure 1b), the main or sub-main pipe is shortened to the plot center. The only required valve outlet, which is a pivot elbow rotation valve for the single lateral, will be installed at the end of the mainline in the center of the irrigated land. Here is where the hand-move lateral is connected, which rotates on a circular basis around the center like a center-pivot system. 

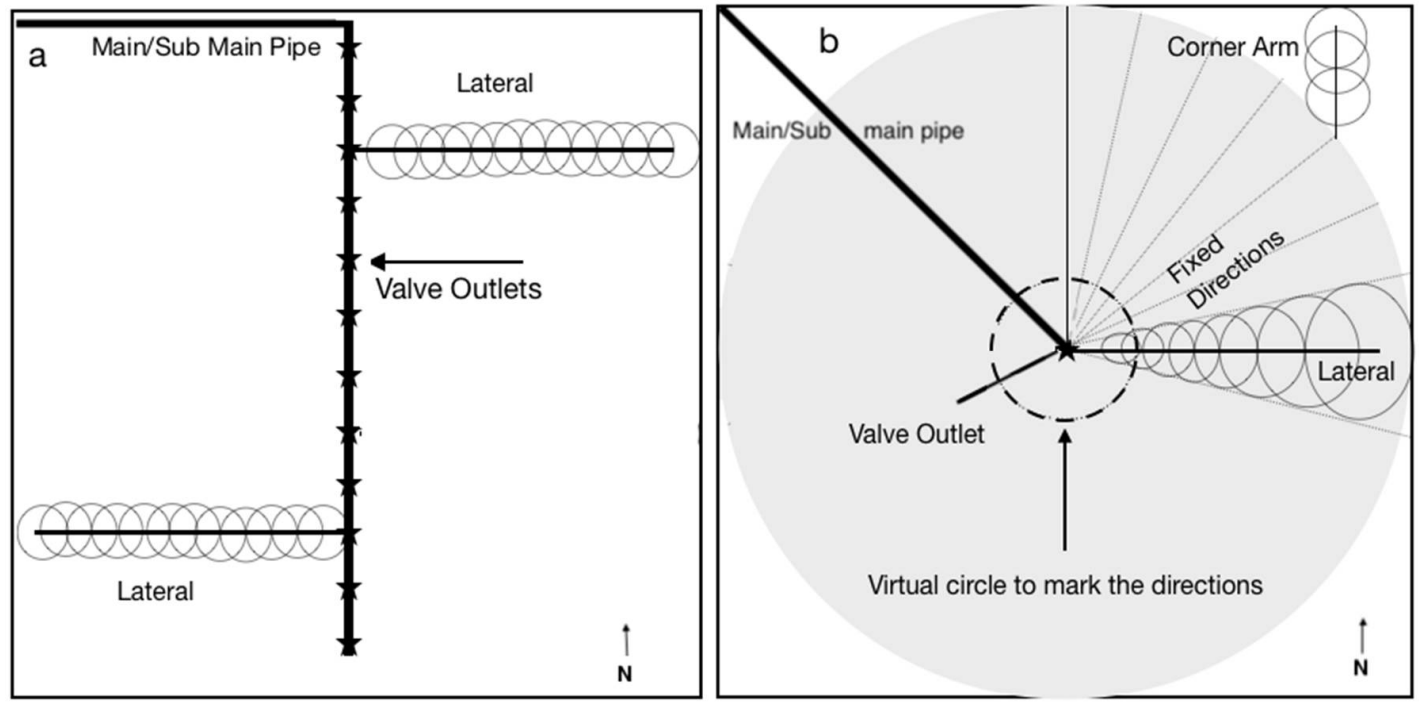

Figure 1. Schematic semi-permanent split lateral (a), and CHL irrigation system (b) comparison.

To examine and introduce the CHL layout, the system has been implemented and tested during 2 months (from 1 March to 30 April 2018) for a small plot of 2 acres. A water distribution uniformity test, according to the lower quarter Christianson uniformity coefficient $\left(\mathrm{DU}_{\mathrm{LQ}}\right)$ method, applying cans to harvest water from sprinklers or catch can method, was done [21]. An economic comparison between ordinary semi-permanent designation and CHL was developed in the capital and annual costs [22,23] and cost-saving items. Component requirements, sprinkler distance optimization for water distribution patterns modification, as well as implementation feasibility have been carried out.

\section{Materials and Methods}

The experiment was done in a $92 \mathrm{~m} \times 92 \mathrm{~m}$ farm in the Nanning Irrigation Test Center, Agricultural Academy of Science (Nanning, Guangxi, China). For a small size farm irrigation system designation, an ordinary split lateral semi-permanent with 2 laterals and a CHL with 1 lateral were designed. The pipes used were PVC tubing to ease the installation, fixing and moving process. The water resource was from a water distribution system in the farm (supplied from the Wuming river) with a $5 \mathrm{~L} / \mathrm{S}$ maximum discharge rate at the Southeast side of the plot. The plot was almost flat with no slope.

\subsection{System Designation}

The soil type was loam as per soil texture triangle, according to soil texture examination results. The soil infiltration rate (I) was $13 \mathrm{~mm} / \mathrm{h}$ with the soil water holding a capacity of $170 \mathrm{~mm} / \mathrm{h}$. Evapotranspiration (ETp) for the site was equal to $5 \mathrm{~mm} / \mathrm{d}$ and irrigation systems efficiency $\left(\mathrm{E}_{\mathrm{a}}\right)$ $80 \%$ was assumed. Maximum allowable depletion (MAD) was equal to 0.55 , the selected plant was sugarcane with $1.2 \mathrm{~m}$ root depth and 1.2 crop coefficient $\left(\mathrm{K}_{\mathrm{C}}\right)$. Crop evapotranspiration $(\mathrm{ETc})$ equaled to $6 \mathrm{~mm}$ /day (Equation (1)) [24]:

$$
\mathrm{ET}_{\mathrm{C}}=\mathrm{ET}_{\mathrm{P}} \times \mathrm{K}_{\mathrm{C}}=1.2 \times 5=6 \mathrm{~mm}
$$

Hence the net irrigation depth (d) will be (Equation (2)) [24]:

$$
\mathrm{d}=\text { Root depth } \times \text { MAD } \times \text { Soil water holding capacity }=1.2 \times 0.55 \times 170=112.2 \mathrm{~mm}
$$

and gross irrigation depth is accounted as below (Equation (3)) [24]: 


$$
\frac{\mathrm{d}}{\mathrm{Ea}}=\frac{112.2}{0.8}=140 \mathrm{~mm}
$$

Based on the above values, the watering cycle was calculated using the below formula and selected 15 days for both ordinary semi-permanent and CHL systems (Equation (4)) [24]:

$$
\frac{\mathrm{d}}{\mathrm{ETC}}=\frac{112.2}{6}=16.6>15 \text { days }
$$

Different sprinkler/sprayer types were used for CHL in which those sprinklers closer to the center would cover a minor area with a shorter distance of throw, while water would be dispersed in a much bigger circle and higher rate at the outermost sprinklers [25] like in the center-pivot systems. The sprinklers discharge rate was chosen to be lower than the soil infiltration rate to avoid runoff and was calculated for each sprinkler separately since the sprinkler and lateral distance in CHL were different to the split lateral semi-permanent. Normally the maximum sprinkler discharge rate (q) is calculated as Equation (5) without the coefficient of 0.86 , where we have a square shape pattern among any 4 sprinklers, however, for $\mathrm{CHL}$, as the lateral movement is like a clock hand, it will form a trapezius pattern in the covering area among 4 sprinklers. Therefore, $\mathrm{q}$ was adjusted based on the experimental coefficient $(\alpha)$ for each sprinkler. To minimize the changes in this formula and also simplify the calculations, the coefficient $\alpha$ as the ratio of the trapezoid area between 4 sprinklers to the assumed rectangle area between 4 sprinklers, is added as per Formula 6 . The maximum discharge rate for the CHL outmost sprinkler is calculated via the below equation (Equation (5)) [24]:

$$
\begin{aligned}
\mathrm{q}=\frac{0.86 \times \mathrm{I} \times \mathrm{Sl} \times \mathrm{Sm}}{3600} & =\frac{0.86 \times 13 \times 11 \times 12}{3600}=0.41 \mathrm{~L} / \mathrm{S} \\
\alpha & =\frac{b+a}{2 a}
\end{aligned}
$$

where: q: Sprinkler maximum discharge rate in L/S, I: Soil infiltration rate in $\mathrm{mm} / \mathrm{h}, \mathrm{S}_{1}$ : Sprinklers distance on lateral in $\mathrm{m}, \mathrm{S}_{\mathrm{m}}$ : Laterals distance in $\mathrm{m}$.

A conventional head to head design [26] for sprinklers, to maximize the coverage of intersecting irrigated circles, is applicable for CHL. However, due to the additive throw distance along the lateral, each sprinkler was covered $45 \%$ by its prior sprinkler (smaller overlap) and $55 \%$ by its next sprinkler in line (bigger overlap). With this, the trapezius area between each four sprinklers was fully covered. This concept has been illustrated in the above figure with the sprinklers radiuses (Figure 2). In fact, the outmost sprinkler will assign the lateral distance and the rest of sprinklers' radiuses accordingly, to cover the area between the two lateral movements, as per the guidelines.

Considering the discharge rate, sprinkler price and available brands in the market, China Drip brand (RS5022-7 model) for the outmost sprinkler was used with a $12 \mathrm{~m}$ throw distance, 2 nozzles and a $0.33 \mathrm{~L} / \mathrm{S}$ discharge rate, which was working under 3-bar pressure. A total of 8 sprinklers on lateral were used and an additional 2 were installed on the corner arm to irrigate the square corners (technical details are mentioned in Appendix A for the rest of the sprinklers). Lateral distance was chosen equal to $12 \mathrm{~m}$ to minimize the number of set moves to 22 , which means approximately each $16^{\circ}$ on the circle there was one irrigation set move. The sprinkler distance between the outmost and the penultimate sprinkler was chosen $11 \mathrm{~m}$ for CHL. The rest of sprinklers were selected according to required radiuses (starting from $2.5 \mathrm{~m}$ with $0.02 \mathrm{~L} / \mathrm{S}$ discharge rate using micro sprayers) to fit in the space between the two lateral movements. If the soil infiltration rate allows, a higher discharge rate set of sprinklers can minimize the number of set moves (covering a bigger area) or system working hours (higher discharge rate). Along the lateral, constant discharge sprinklers are used so that when the operation presser exceeds a level, it will not impact on their discharge rate. For one of the sprayers, due to the limited available options, a pressure regulator was used to lower down the pressure for that particular sprayer at 2-bar (Figure 3). 


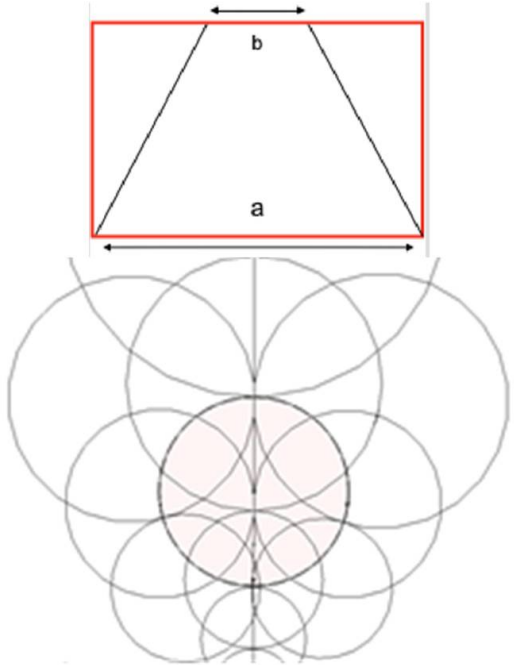

(a)

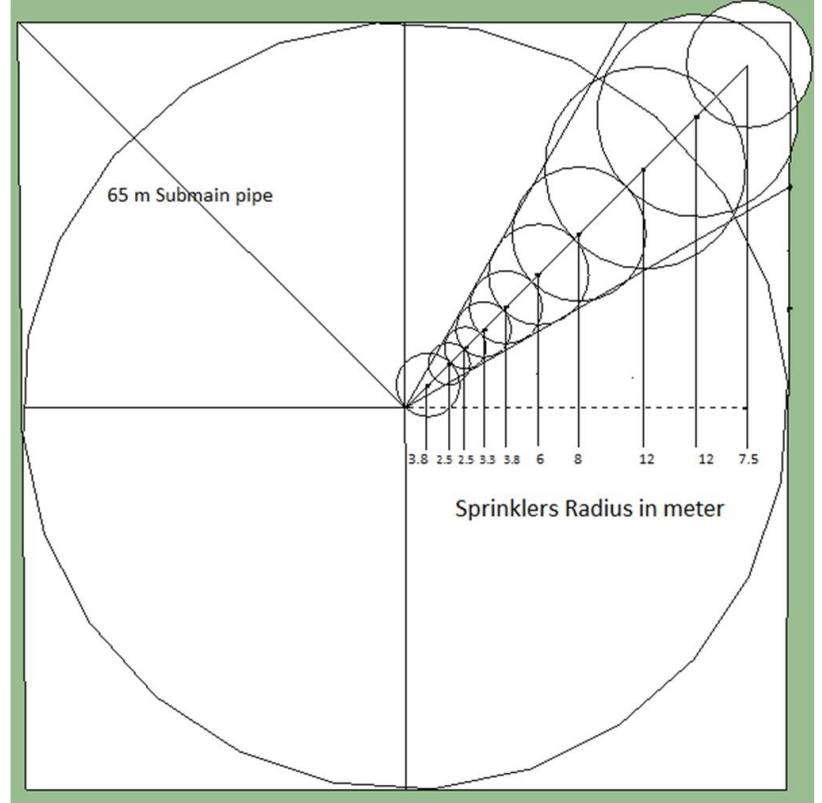

(b)

Figure 2. (a) CHL sprinklers overlapping and (b) radiuses along the lateral.

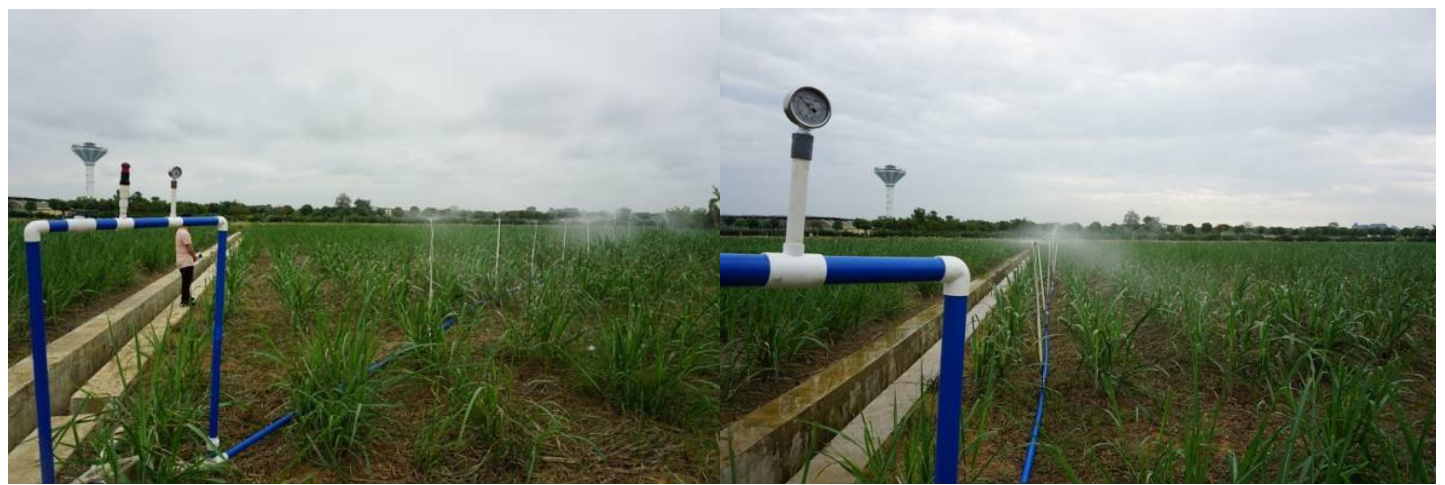

(a)

(b)

Figure 3. (a,b) CHL irrigation system working in two different positions.

Total lateral length was $42 \mathrm{~m}$ and an additional $16 \mathrm{~m}$ was added as a corner arm. The arm was split to two parts with 2 sprinklers equipped with shutoff valves and rotation elbows, in which both parts were able to rotate or be closed, therefore the arm could be crooked to the corners whenever necessary (Figure 4a). The arm length is normally around 1/3 of the lateral as a function of distance between the square corner and circle circumference as well as the sprinkler radius. Fixed directions for the lateral around the irrigated circle were marked to guarantee following the same pattern in each revolution. It is done via placing flags on a virtual circle around the plot to specify where the next lateral directions must be (Figure $4 \mathrm{~b}$ ).

For the split lateral, the same sprinkler type as the CHL outmost sprinkler was used (China Drip brand, RS5022-7 model) with $11.5 \times 11.5 \mathrm{~m}$ as $\mathrm{S}_{\mathrm{l}} \times \mathrm{S}_{\mathrm{m}}$. A total of 8 sprinklers working concurrently on 2 laterals to move lengthwise. A total system discharge rate of $2.67 \mathrm{~L} / \mathrm{S}$ for split lateral was designed, while it was accounted as equal to a maximum $1.33 \mathrm{~L} / \mathrm{S}$ for CHL. The essential designation criteria of both systems are calculated and summarized in Table 1. For the CHL, the mentioned sprinkler type is the outmost sprinkler. 
To calculate the friction loos and total dynamic head (TDH), Hazen William equation was used, taking into account the velocity margin to check the pipe's diameter and select the pump $[27,28]$. An additional 10\% was accounted on the TDH to compensate the friction losses along the lateral. In this experiment, the wind impact was negligible as the test center area was not affected by wind. The difference between required components for CHL and split lateral semi-permanent are summarized in Table 2 below. Items with the same cost for both systems have not been mentioned here (such as pressure gauge, air release valve, pump and power unit with the installation fee, filter, system implementation fee, transferring to the site, etc.); however, they have been calculated in the total cost for each system. Energy consumption in $\mathrm{Kw} \mathrm{h}$ was measured as a function of system total discharge rate multiplied by TDH and the system working hours, divided by the pump efficiency [29].

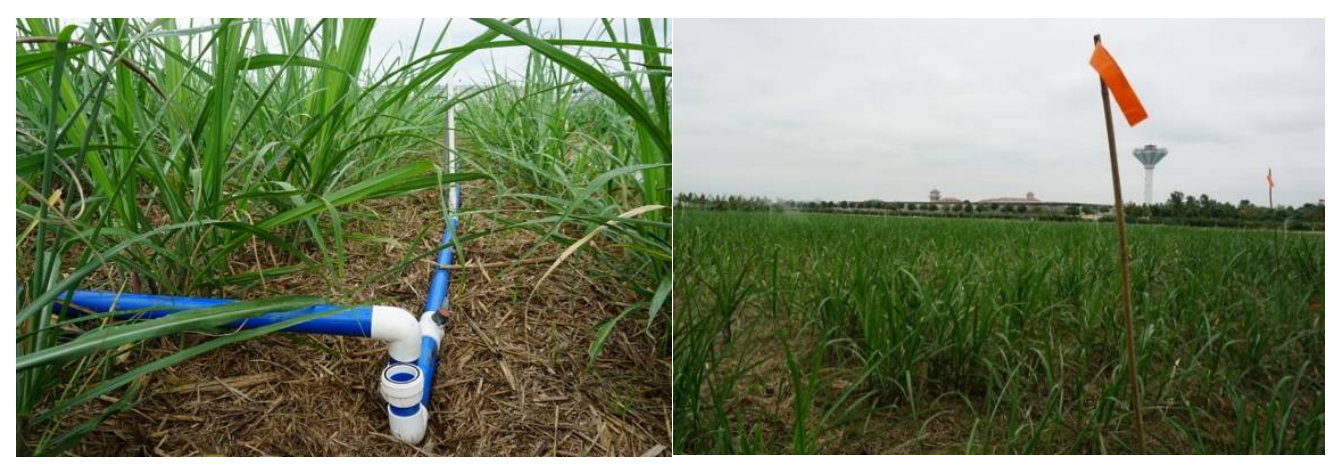

(a)

(b)

Figure 4. (a) CHL arm with rotating elbows and shutoff valve and (b) flags placed in the farm.

For split lateral semi-permanent, a 3" PVC pipe was laid as the mainline from the water source to the middle of the farm and from there extended to the end, as shown in the schematic Figure 1, to feed the two laterals. Forty-six meters $(46 \mathrm{~m})$ of the mainline 2" pipe was used as it was designed to be telescopic. For CHL, since the system works with a lower flow rate, therefore only a 2" diameter PVC was used as mainline, which is directly extended to the center as there was no hydrant required along the designed direction. Based on the outcomes, both systems required materials and cost comparison has been discussed and analyzed in the following section.

Table 1. Semi-permanent and CHL systems designation parameters.

\begin{tabular}{ccc}
\hline Item & Semi-Permanent & CHL \\
\hline Sprinkler Type (China Drip) & RS5022-7 & RS5022-7 \\
Sprinkler Working pressure (m) & 30 & $20-30$ \\
Sprinkler Flow rate (L/S) & 0.33 & $0.02-0.33$ \\
Radius or throw distance (m) & 12 & $2.5-12$ \\
Sprinklers distance (m) & 11.5 & $2.7-11$ \\
Laterals distance (m) & 11.5 & 12 \\
Number of laterals & 2 & 1 \\
Set move per day (times) & 2 & 2 \\
System total discharge rate (L/S) & 2.67 & $1.02 *$ \\
Spraying intensity (mm/h) & 9.1 & 10.6 \\
TDH (m) & 36.3 & 35 \\
Watering cycle (days) & 15 & 15 \\
Required water depth (mm) & 112 & 112 \\
Required watering time (h) & 12 & 10.6 \\
Hydromodule (L/S/ha) & 0.84 & 0.96 \\
\hline
\end{tabular}

Note: * Average total discharge rate considering the corner arm. 
Table 2. Semi-permanent and CHL system components comparison.

\begin{tabular}{ccc}
\hline Item & Semi-Permanent & CHL \\
\hline Number of sprinklers/sprayers & 8 & 10 \\
PVC pipe 3" for mainline (m) & 86.25 & 0 \\
PVC pipe 2" for mainline (m) & 46 & 65 \\
PVC pipe 2" for laterals (m) & 80.5 & 58 \\
0.6 m 2" raiser to connect mainline and lateral (m) & 4.8 & 0.6 \\
PE pipe 1" as riser (m) & 12 & 15 \\
Hydrant & 8 & 1 \\
Fittings (elbow, tee branch, valves, coupling, reducers) & 58 & 44 \\
0.6 m deep trench for the main/sub mainline (m) & 133 & 65 \\
Working hours per year & 645 & 1521 \\
Required energy (kw) & 875.5 & 760.5 \\
Water used per year $\left(\mathrm{m}^{3}\right)$ & 6184 & 5359 \\
\hline
\end{tabular}

\subsection{Catch Can Test}

Water distribution pattern uniformity to measure the water application depth and sprinklers coverage was tested using catch can method at the site [30]. Four different runs were performed to measure the amount of water given to the farm in different spots between the two lateral movement areas. Disposable cups (with a stone inside to avoid falling) were used to collect the samples. Beakers were applied to measure the volume of water after each $45 \mathrm{~min}$ of irrigation and the measurement was redone for the same area following the next lateral move. According to catch can method, a table was prepared to record the measured date. With this, the horizontal and vertical coverage were also monitored. A total of 180 cans were placed in 3 rectilinear layouts. Every $1 \mathrm{~m}$ along the pipe a cup was placed radial and a total of 3 caps horizontally to cover the full throw distance of each sprinkler. The can's distances were varying horizontally between two lines (as illustrated in Figure 5) since we have different radiuses along the lateral. The can diameter and area were measured to calculate the irrigation rate. The average of the collected water in all the cans was calculated to be divided by the can area and the time consumed to collect this volume of water. The average of the lowest $25 \%$ of the results were taken to be divided by the average of all the results as low quarter distribution uniformity or DU [31].

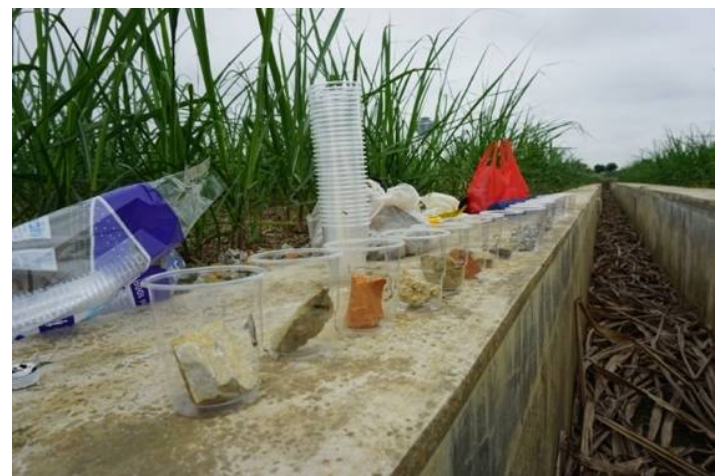

(a)

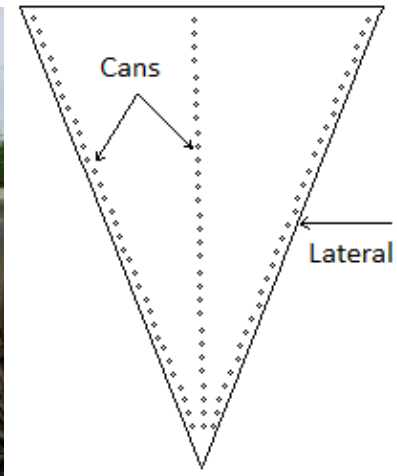

(b)

Figure 5. (a) Cups numbered and placed in (b) 3 rectilinear pattern for uniformity measurements.

\section{Results and Discussions}

\subsection{Economical Comparison}

This novel system shows a much lower capital cost required compared to the traditional layout. The cost comparison has been carried out considering the system component costs as well as annual 
operation costs. Table 3 is showing a brief summary of the main item's costs for both layouts in the tested farm for comparison and control. Even though the item's costs might vary in different countries, nonetheless the ratio evaluation can clarify the hypothesis. Based on the results, CHL requires a 37.5\% lower capital cost and an $11.2 \%$ lesser annual cost compared to ordinary semi-permanent layouts. The lower component cost will cause lower annual maintenance fees, lower depreciation and repair cost for equipment, as well as lesser insurance, tax cost and interest (or opportunity cost) which are calculated as $2.5 \%$ up to $3.3 \%$ of the total cost. The system also has $10 \%$ lower water and $13 \%$ lesser energy consumption. Total dynamic head accounted for 3.5\% lower CHL. As the CHL system works with a lower discharge rate and TDH, a lower horsepower pump (1 HP) was required compared to the split lateral (2 HP pump). Outcomes revealed that the main cause of the capital cost reduction in clock hand layout is using smaller lengths of pipes with lower diameters, while other items such as sprinklers, hydrants and fittings have lesser cost saving impacts. There were 10 sprinklers/sprayers used for CHL and 8 for split lateral, however, as the sprinklers size and throw distances reduce towards the center in $\mathrm{CHL}$, the total amount spent for sprinklers was lower than ordinary semi-permanent. The new layout will also need a smaller filter and tank. In addition, the 3" size fittings for the split lateral system would be 2 " in CHL, which have a lower price. The system total working hours is higher for CHL.

Table 3. Semi-permanent and CHL cost comparison for a 2-acre farm in USD.

\begin{tabular}{ccc}
\hline Item & Semi-Permanent \$ & CHL \$ \\
\hline Mainline pipe cost & 394 & 130 \\
Sprinklers & 32 & 22 \\
2" PVC pipe for laterals and 0.6 m raiser & 170.5 & 117 \\
Hydrant valve & 20 & 2.5 \\
1" raiser pipe (1.5 m) & 12 & 15 \\
Fittings (tee branch, elbow, valves, coupling, reducer etc.) & 149 & 92 \\
Others (tank, pressure gage, air valve, filter, etc.) & 184 & 137 \\
Main pipe bury fee & 22 & 11 \\
System implementation and transfer fee & 134 & 114 \\
Pump and Power unit with installation fee & 228 & 200 \\
Total Capital Cost & 1345.5 & 840.5 \\
Energy cost per year & 65.5 & 57 \\
Annual maintenance, repair \& replacement (at 3.3\%) & 44 & 28 \\
Insurance and Taxes (at 2.5\%) & 33 & 21 \\
Annual interest (at 3.3\%) & 45 & 28 \\
Water cost & 30 & 27 \\
Farm machinery costs & 190 & 190 \\
Farm seed, fertilizer \& pesticide & 97 & 97 \\
Total Estimated Annual Cost & 504.5 & 448 \\
\hline
\end{tabular}

Analyzing the results proves up to $37.5 \%$ cost saving for the initial investment for the clock hand layout irrigation system. It will cause a shorter time required for the project return of investment (lower break-even point). Especially since the first few years would be critical years with the highest financial stresses for the farmers; therefore, it will be a good alternative to implement a sprinkler system with a lower initial investment. There will also be a $11.2 \%$ reduction in the annual costs for CHL, hence, over the long term the system is a lot cheaper than the traditional semi-permanent layout. Figure 6 shows the accumulative grand total cost (initial capital cost + annual costs) comparison between the two systems during 20 years after the implementation. In fact, clock hand layout has an almost $14.4 \%$ lower grand total cost compared to semi-permanent set-move, even during the 20 years, which is the project time horizon. For a semi-permanent total, 673 USD per acre capital cost was calculated while it was accounted as 420 USD per acre for CHL.

The grand total cost difference in percentage between the clock hand layout and split lateral semi-permanent systems over a longer term has been graphically presented in Figure 7. As can be 
seen, the graph shows at the beginning of the project there is a significant gap between CHL and split lateral, which is a $37.5 \%$ difference. The difference will lessen over time as the annual costs are added in and the total amount are bigger values. Therefore, the capital cost will be a smaller proportion of it. The graph will reach almost $17.2 \%$ difference during the next 10 years. The line will not evanesce to zero value even after 100 years, which is much greater than any irrigation project lifetime.

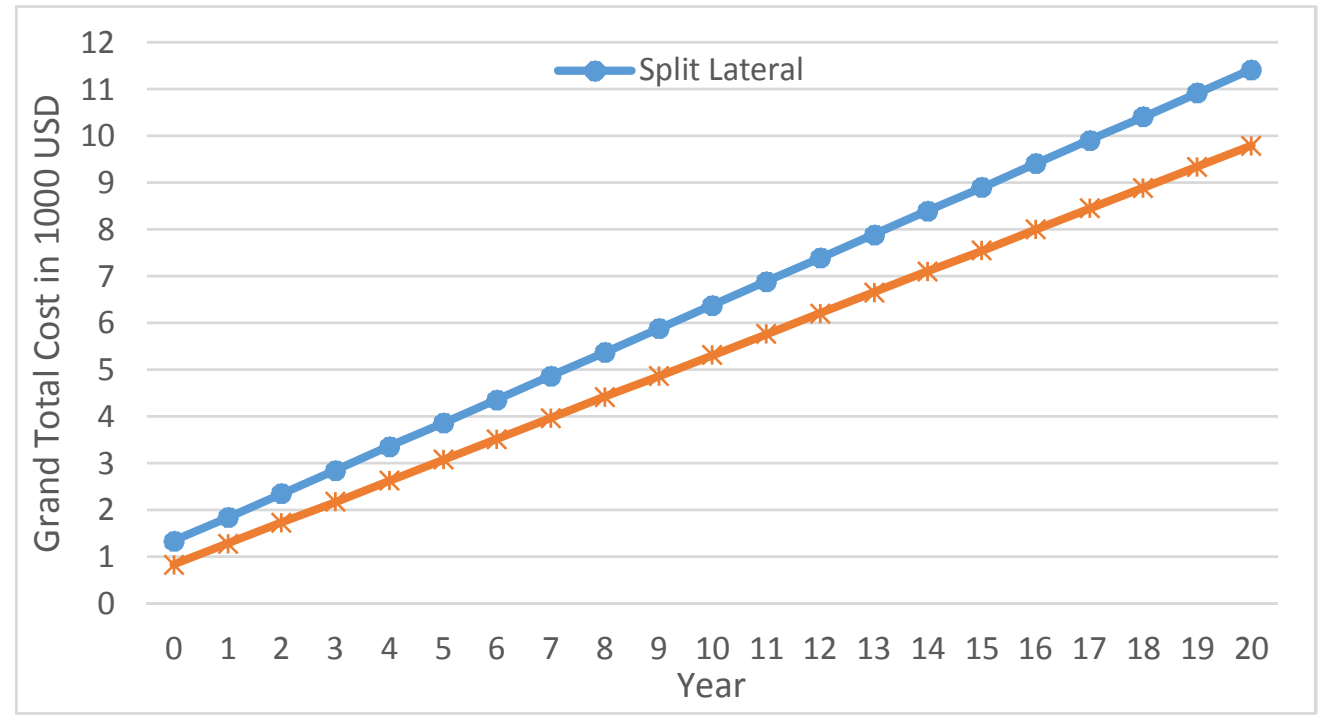

Figure 6. Accumulative total cost comparison in 1000 USD during 20 years for split lateral and CHL.

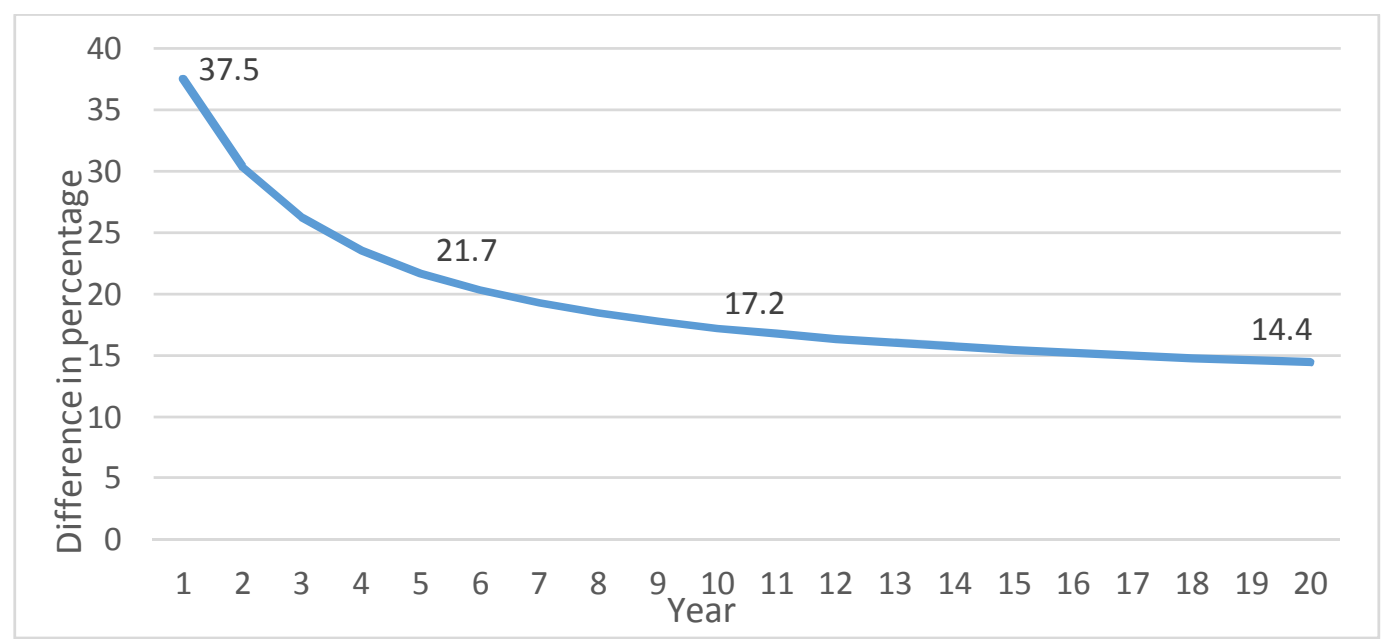

Figure 7. Percentage total cost difference between the two systems during 20 years.

\subsection{Catch Can Result}

To calculate the irrigated rate at 50 PSI pressure, the can bottom diameter was measured at $5 \mathrm{~cm}$ with $19.63 \mathrm{~cm}^{2}$ area. The total can volume was $200 \mathrm{ML}$. The average of the collected water in all the cans was calculated as $15 \mathrm{~mL}$, which was divided by the can area and the time consumed ( $45 \mathrm{~min})$ to collect the volume of water as $10.5 \mathrm{~mm} / \mathrm{h}$. During the first run of the test, having low values in one area showed a deficiency which the under irrigated area's sprinkler was not performing efficiently and therefore it was replaced. To calculate $\mathrm{CU}_{\mathrm{LQ}}$ or low quarter distribution uniformity, the average of the lowest $25 \%$ of the results ( 45 cans) was accounted for $6.6 \mathrm{~mm}$. This amount was divided by the average of the results for all the 180 cans $(7.7 \mathrm{~mm})$. 
Along the radial legs an $86 \%$ uniformity in average was achieved which can justify the system performance compared with 70-75\% in drip irrigation [32], 74-90\% for linear and center-pivot systems [33]. It is due to the fact that almost all the sprinklers had a bell-shaped or triangular-shaped distribution pattern. If the sprinkler works under low pressure, it will have a distribution pattern more like a donut shape [19]. The catch can results demonstrated that the sprinklers in between the two lateral have an acceptable coverage. Taking into account the new pattern in which one sprinkler was covered $55 \%$ by its next and $45 \%$ by its previous sprinkler, the below figure (Figure 8 ) illustrates the coverage pattern in CHL, which on average one side of the sprinkler will receive $14 \%$ less water compared to the other side of it.

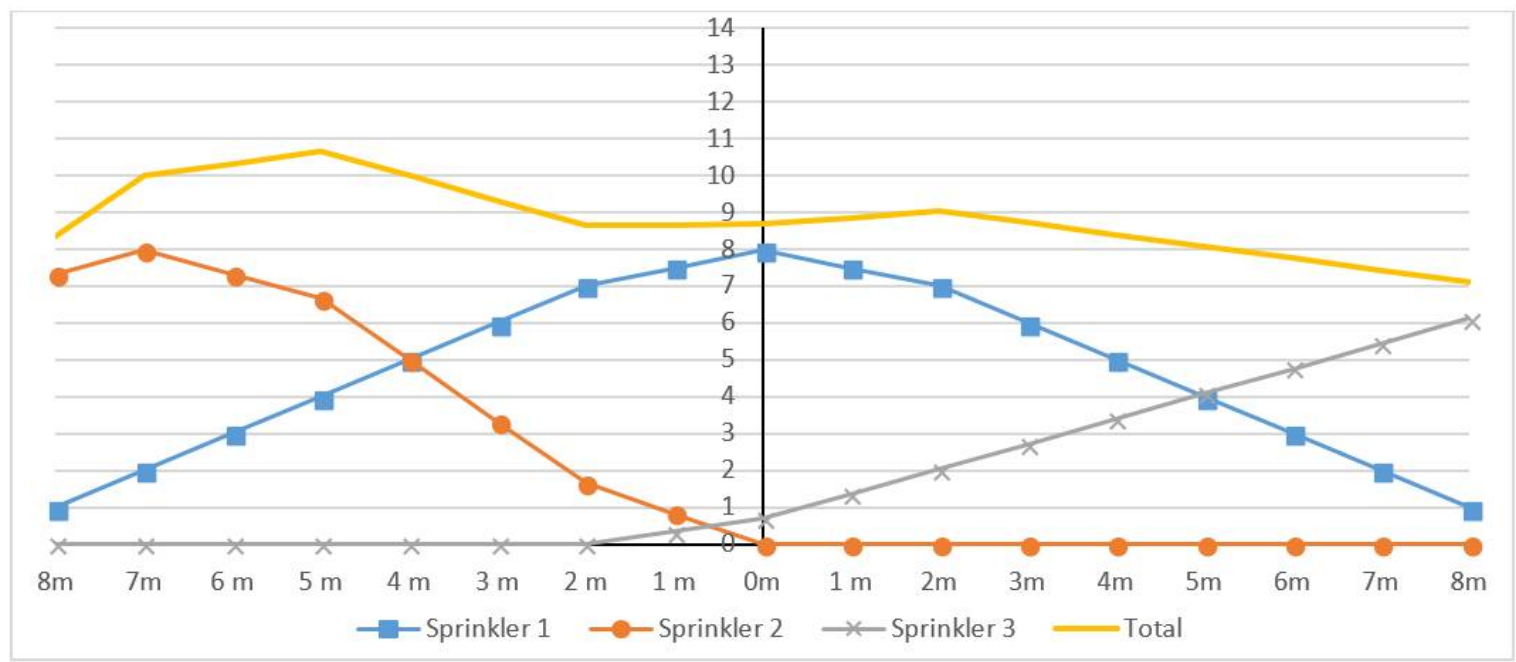

Figure 8. Water depth in $\mathrm{mm}$ and distribution uniformity pattern around the irrigated circle of a CHL sprinkler with $8 \mathrm{~m}$ distance of throw.

Results indicated a high sensitivity of uniformity in CHL to the sprinklers discharge rate and distance of throw (which varies along the lateral) as the most important factor. In this case there will be some spots under- or over-irrigated, re-nozzling might be required to balance the amount of water distributed and avoid yield variation. The wind impact was negligible in this study, however, in windy situations, especially in small size farms which the wind impact is greater [34], the beginning of the lateral (at the plot center), where the sprayers are, will be the most affected area. Hence, to avoid wind drift and evaporation losses, according to the wind speed [35], the center point of the circle for CHL can be shifted against the wind direction to minimize the wind impact on the distribution pattern.

Overall, in reference to the above results, the advantages of this new layout include:

1. Reducing the main pipe length to $50 \%$ in square shape and $70 \%$ in rectangular shape plots.

2. Main/sub-main pipe diameter reduction due to lower system total discharge.

3. Number of laterals will be reduced to half.

4. Reduction in the number and size of required fittings.

5. The number of required valve outlets (hydrants) will decrease to one.

6. Ease of carrying from one set to the next, especially due to having less laterals, which unlike split lateral layout, traveling from one side of the plot to another is not required.

7. After completing a cycle, the lateral will be where the irrigation started and there is no need to move back to the starting point.

8. User-friendly system, specially reducing the need for connecting and disconnecting the lateral to different outlet valves.

9. Minimum maintenance requirement. 
10. Unlike high cost and high maintenance center pivots, this system suits smaller units.

11. Less land forming is required as the movement is manual.

12. There will be no wheel rut damage in the land for CP systems.

13. Lesser TDH.

14. Lower system discharge rate.

15. Smaller horsepower pump requirement.

16. Lesser energy cost.

17. Total water utilization will be reduced.

18. Lesser insurance and tax cost.

19. Lower depreciation and interest cost.

The system also has similar disadvantages with both, semi-permanent set-move and center-pivot irrigation systems such as:

20. Circular pattern watering which results in having less than $80 \%$ of the plot being well irrigated. However, applying corner arm would almost solve this problem, especially because the hand carry method provides simplicity to install a corner catcher wherever needed to increase the irrigable land with no complications. Installing a large gun sprinkler at the end of a lateral (like center pivot system) is also another option.

21. Longer annual irrigation time compared to semi-permanent split lateral. In fact, the number of lateral movements for one evolution in CHL will be 37\% higher than the set-move split lateral layouts since the system works with a lower outflow rate and at the same time it requires shorter irrigation periods per cycle up to $14 \%$. For this problem, larger distance throw sprinklers are advisable or if permeability of the soil infiltration rate allows, applying sprinklers with higher a discharge rate can minimize the required time.

22. Like the set-move split lateral, the CHL requires manual work. With regards to the system feasibility, as per experiment, the amount of manual work will be higher in clock hand lateral since there will be more pipes to transfer to the next position, which will also cause more damages to the cultivated crops. For this examination, in one revolution the farmer will need to carry 7 pieces of pipes (6 to 9-m length) on 1 lateral for 22 times (total of 154 times) with $4 \mathrm{~km}$ traveling distance in total, while for split lateral it is 10 pieces of pipes (6 to 9-m length) on 2 laterals for 8 times (total of 80 times) with $3 \mathrm{~km}$ total traveling distance.

\section{Conclusions}

Insufficient freshwater resources, especially in water stressed zones, can lead to inadequate food production and poverty in some regions in the near future. Sprinkler irrigation systems can optimize water utilization efficiency and maximize annual yield, which is beneficial for farmers and for the public. Pressured irrigation methods are costly for farmers in most cases, which requires time for reimbursement. While insignificant financial support by governments in some countries makes those expensive to invest in, new technologies can offer affordable sprinkler irrigation systems. As shown above comparatively, the new set-move layout in the present study has offered an adaptable and cheap sprinkler method with more than 37\% less capital cost requirement and $11 \%$ lower annual expenses. The feasibility of this inexpensive system (the cheapest if it is designed as fully portable), especially in small scale implementation, encourages farmers to use sprinkler systems.

Clock hand lateral (CHL) layout is a cost-saving combination of the two current sprinkler irrigation systems, namely semi-permanent split lateral set-move and center-pivot. The main pipe (or sub main) in this design is extended to the center of the farm only, and there it will be connected to a single or double lateral (depending on the farm size) which transfers around the center. In addition, the total number of valve outlets installed on the mainline is limited to one only, which will be placed at the end of the main/sub-main pipe. It saves cost in most irrigation system elements including the length and diameter of the main pipe, number of laterals and sprinklers, fittings and hydrants. The system 
has also shown an $86 \%$ distribution uniformity. As the system is manual, reliable manpower would be essential to operate the system efficiently. In most Asian and African countries with small estate land owners, this system would be a good pressured irrigation system option with minimum capital and annual costs. Therefore, such an irrigation system, owing to its new arrangement, can be a competitive design, allowing smaller farms to level up and enjoy the benefits. Economic advantages for the public can promote applying irrigation systems, which will lead to a more cost-effective water application and efficient water resource saving and/or management, taking into consideration the importance of water resources and sustainable development.

Author Contributions: L.G. methodology, writing and review, S.R. project administration, conceptualization and writing the original draft, editing, X.C. and R.F. supervision, validation and visualization, L.Y. formal analysis and data curation, and S.S. resources.

Funding: This research was funded by Natural Science Foundation of China (Code: 41501230, Code: 41761048) and the Guangxi Natural Science Foundation (Code: 2016GXNSFAA380197).

Conflicts of Interest: The authors declare no conflicts of interest.

\section{Appendix}

Table A1. Sprinkler/Sprayer technical details.

\begin{tabular}{cccc}
\hline Model & Radius $(\mathbf{m})$ & Discharge Rate (L/H) & Working Pressure (Bar) \\
\hline MS3008 & 3.8 & 278 & 3 \\
MS8070 & 2.5 & 77 & 3 \\
MS8070 & 2.5 & 77 & 3 \\
MS3006 & 3.3 & 144.8 & 2 \\
MS3008 & 3.8 & 278 & 3 \\
Butterfly Nozzle & 6 & 444 & 3 \\
SP3303 & 8 & 625 & 3 \\
RS5022-7 Double-nozzle & 12 & 1200 & 3 \\
RS5022-7 Double-nozzle & 12 & 1200 & 3 \\
SP3302 & 7.5 & 510 & 3 \\
\hline
\end{tabular}

\section{References}

1. Shiklomanov, I.A. Appraisal and Assessment of World Water Resources. Water Int. 2000, 25, 11-32. [CrossRef]

2. Food and Agriculture Organization of the United. AQUASTAT Online Database; FAO: Rome, Italy; Available online: http:/ / www.fao.org/nr/water/aquastat/irrigationmap/index.stm (accessed on 12 June 2018).

3. Siebert, S.; Döll, P.; Feick, S.; Hoogeveen, J.; Frenken, K. Global Map of Irrigation Areas, Version 4.0.1; Johann Wolfgang Goethe University, Frankfurt am Main, Germany/Food and Agriculture Organization of the United Nations: Rome, Italy, 2007.

4. The State of the World's Land and Water Resources for Food and Agriculture. Managing Systems at Risk; Summary Report; FAO: Rome, Italy, 2011; p. 9.

5. Gleick, P.H. Water in Crisis: A Guide to the Worlds Fresh Water Resources; Oxford University: Oxford, UK, 1993; Chapter 2; p. 13.

6. Oster, J.D.; Wichelns, D. Economic and agronomic strategies to achieve sustainable irrigation. Irrig. Sci. 2003, 22, 107-120. [CrossRef]

7. Ganjegunte, G.; Clark, J. Improved irrigation scheduling for freshwater conservation in the desert southwest U.S. Irrig. Sci. 2017, 35, 315-326. [CrossRef]

8. Battikhi, A.M.; Abu-Hammad, A.H. Comparison between the efficiencies of surface and pressurized irrigation systems in Jordan. Irrig. Drain. Syst. 1994, 8, 109-121. [CrossRef]

9. Krutz, L.J.; Irby, T.; Golden, B.; Pringle, L.; Falconer, L. Improving Furrow Irrigation Efficiency; Mississippi Soybean Promotion Board Project No. 54-2013 Annual Report; Mississippi Soybean Promotion Board: Canton, MS, USA, 2014. 
10. Smajstrla, A.G.; Boman, B.J.; Clark, G.A.; Haman, D.Z.; Harrison, D.S.; Izuno, F.T.; Pitts, D.J.; Zazueta, F.S. Efficiencies of Florida Agricultural Irrigation Systems; Agricultural and Biological Engineering Department, Florida Cooperative Extension Service, Institute of Food and Agricultural Sciences, University of Florida: Gainesville, FL, USA, 1991.

11. Daoud, R.; Peter, M.; George, A.; Dani, F. Efficiency of drip irrigation system for «paulownia» trees in the Aakkar coastal plain of Lebanon. Int. J. Plant Anim. Environ. Sci. 2017. [CrossRef]

12. Al-Jamal, M.S.; Ball, S.; Sammis, T.W. Comparison of sprinkler, trickle and furrow irrigation efficiencies for onion production. Agric. Water Manag. 2001, 46, 253-266. [CrossRef]

13. Hamdy, A. Water use efficiency in irrigated agriculture: An analytical review. In Water Use Efficiency and Water Productivity: International Centre for Advanced Mediterranean Agronomic Studies; WASAMED Project; Bertrand Hervieu Publication: Amman, Jordan, 2005; pp. 9-19.

14. Laycock, A. Irrigation Systems, Design, Planning and Construction; CABI: Oxfordshire, UK, 2007; pp. 170-185.

15. Martínez, J.M.; Martinez, R.S.; Martín-Benito, J.T. Analysis of water application cost with permanent set sprinkler irrigation systems. Irrig. Sci. 2004, 23, 103-110. [CrossRef]

16. Ortiz Romero, J.N.; Montero Martínez, J.; Martínez, R.S.; Tarjuelo Martín-Benito, J.M. Set Sprinkler Irrigation and Its Cost. J. Irrig. Drain. Eng. 2006, 132, 445-452. [CrossRef]

17. Montero, J.; Martínez, A.; Valiente, M.; Moreno, M.A.; Tarjuelo, J.M. Analysis of water application costs with a center pivot system for irrigation of crops in Spain. Irrig. Sci. 2013, 31, 507-521. [CrossRef]

18. Rolland, L. Mechanized Sprinkler Irrigation; FAO Irrigation and Drainage Paper; FAO: Rome, Italy, 1982; Chapter 15; p. 367.

19. Gilley, J.R. Sprinkler Irrigation Systems; Agricultural Engineering Department, Texas A\&M University: College Station, TX, USA, 1996; pp. 291-307.

20. Waller, P.; Yitayew, M. Irrigation Lateral Design-Irrigation and Drainage Engineering; Springer: Cham, Switzerland, 2016; pp. 105-121.

21. American Society of Agricultural and Biological Engineers. Procedure for Sprinkler Testing and Performance Reporting; ASAE S398.1; American Society of Agricultural and Biological Engineers: St. Joseph, MI, USA, 1985.

22. Wang, X. A Study of the Irrigation Water Pricing System in China; Master of Environmental Studies Capstone Projects; Department of Earth and Environmental Science, University of Pennsylvania: Hayden Hall, PA, USA, 2010; p. 13.

23. Zhou, N. Key China Energy Statistics; China Energy Group, Lawrence Berkeley National Laboratory: Berkeley, CA, USA, 2016; p. 26.

24. Amin, A. Pressured Irrigation Systems Design; Agricultural Department, University of Fredousi: Mashhad, Iran, 2006; Volume 2.

25. Marjang, N.; Merkley, G.P.; Shaban, M. Center-pivot uniformity analysis with variable container spacing. Irrig. Sci. 2012, 30, 149-156. [CrossRef]

26. Louie, M.J.; Selker, J.S. Sprinkler head maintenance effects on water application uniformity. J. Irrig. Drain. Eng. 2000, 126, 142-148. [CrossRef]

27. Cuenca, R.H. Irrigation System Design; An Engineering Approach; Department of Agricultural Engineering, Oregon State University; Prentice Hall: Corvallis, OR, USA, 1989; p. 552.

28. Lansey, K.; El-Shorbagy, W. Design of Pumps and Pump Facilities. In Storm Water Collection Systems Design Handbook; McGraw-Hill Professional: New York, NY, USA, 2001; p. 12.

29. Jackson, T.M.; Khan, S.; Hafeez, M. A comparative analysis of water application and energy consumption at the irrigated field level. Agric. Water Manag. 2010, 97, 1477-1485. [CrossRef]

30. Bortolini, L.; Martello, M. Effects of Water Distribution Uniformity on Waxy Corn (Zea mays L.) Yield: Preliminary Results. J. Water Resour. Prot. 2014, 6, 1037-1044. [CrossRef]

31. Merriam, J.L.; Keller, J. Farm Irrigation System Evaluation: A Guide to Management; Utah State University: Logan, UT, USA, 1978.

32. Saidi, A.; Hammami, M.; Daghari, H.; Boughdiri, A.; Ali, H.B. Irrigation Uniformity Impacts on Water Use Efficiency and Soil Salinity: Case Study of Tomato Crop under Trickle Irrigation System in the North-East of Tunisia. J. Hydrogeol. Hydrol. Eng. 2016, 5, 2. [CrossRef]

33. Dukes, M.D.; Perry, C. Uniformity testing of variable-rate center pivot irrigation control systems. Precis. Agric. 2006, 7, 205. [CrossRef] 
34. Dechmi, F.; Playán, E.; Cavero, J.; Faci, J.M.; Martínez-Cob, A. Wind effects on solid set sprinkler irrigation depth and yield of maize (Zea mays). Irrig. Sci. 2003, 22, 67-77. [CrossRef]

35. Yazar, A. Evaporation and drift losses from sprinkler irrigation systems under various operating conditions. Agric. Water Manag. 1984, 8, 439-449. [CrossRef] 